\title{
ANALYSIS OF CAPABILITY OF AIR POLLUTION MONITORING FROM AN UNMANNED AIRCRAFT
}

\author{
Augustyn Chwaleba ${ }^{1}$, Aleksander Olejnik ${ }^{2}$, Tomasz Rapacki ${ }^{3}$, Norbert Tuśnio ${ }^{4}$ \\ ${ }^{1}$ Faculty of Electrical Engineering, Warsaw University of Technology, Pl. Politechniki 1, \\ 00-661 Warsaw, Poland \\ ${ }^{2}$ Faculty of Mechatronics and Aviation, Military University of Technology, \\ Ul. Gen. Sylwestra Kaliskiego 2, 00-908 Warsaw, Poland \\ ${ }^{3}$ AM Technologies Polska Sp. z o. o., Al. Jerozolimskie 146C, 02-305 Warsaw, Poland \\ ${ }^{4}$ Faculty of Fire Safety Engineering, The Main School of Fire Service, \\ Ul. J. Słowackiego 52/54, 01-629 Warsaw, Poland \\ E-mails: ${ }^{1}$ achwaleba@op.pl; ${ }^{2}$ aleksander.olejnik@wat.edu.pl (correspondingauthor); \\ ${ }^{3}$ tomasz.rapacki@amt.pl; ${ }^{4} n t u s n i o @ s g s p . e d u . p l$
}

Received 11 November 2013; accepted 28 February 2014

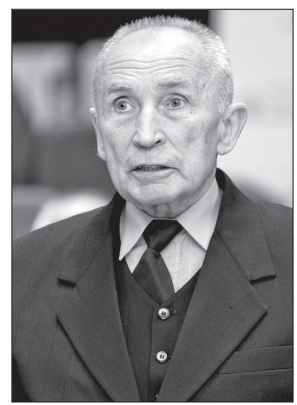

Augustyn CHWALEBA, Prof. Dr Habil, Eng.

Education: MSc (Eng) - Warsaw University of Technology, Faculty of Electrical Engineering, Electrical metrology, 1960; PhD - Warsaw University of Technology, Faculty of Electrical Engineering, Electrical metrology, 1967; DSc - Warsaw University of Technology, Faculty of Electrical Engineering, Electrical metrology, 1980; Professor - Warsaw University of Technology, Faculty of Electrical Engineering, Electrical metrology, 1986.

Affiliations and functions: retired.

Research interests: electrical metrology, measurement signal processing and use of electronics in medicine and environmental protection.

Publications: author and co-author of more than 40 books, about 200 articles and published papers, several patents.

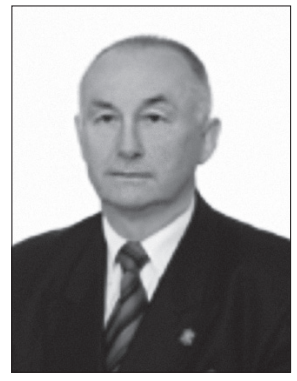

Aleksander OLEJNIK, Prof. Dr Habil, Eng.

Education: MSc (Eng) - Military University of Technology, Faculty of Mechanical Engineering. Mechanics, 1973; PhD - Military University of Technology, Faculty of Mechanical Engineering, Engineering Sciences, 1979; Associate Professor - Military University of Technology, Faculty of Mechanical Engineering, Engineering Sciences, 1988; Professor - Engineering Sciences, 1996.

Affiliations and functions: professor, Military University of Technology, Faculty of

Mechatronics and Aeronautical Engineering, Institute of Aeronautics.

Research interests: statics and dynamics of aircraft structures, aero-elastic surface systems, modeling of aircraft structures.

Publications: author and co-author of 2 monographs and more than 100 scientific articles.

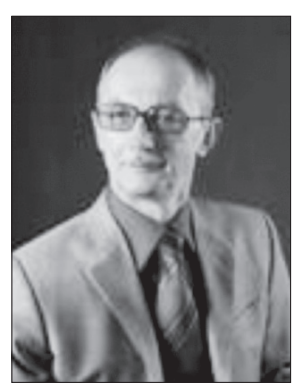

Tomasz RAPACKI, $P h D$, Eng.

Education: MSc (Eng) 1963-1968 - Warsaw Military University of Technology, Faculty of Electronics; 1990 - PhD, Military University of Technology.

Specialization: radar and electronic warfare technology, direction finding and emitter location technology.

Affiliations and functions: 1970-2003 from researcher to director of Institute of Radar Technology, Warsaw Military University of Technology; 2003 to present: AM Technologies Warsaw, Vice President.

Research interests: electronic intelligence technology and signal processing.

Publications: author and co-author of 75 scientific articles and conference papers. 


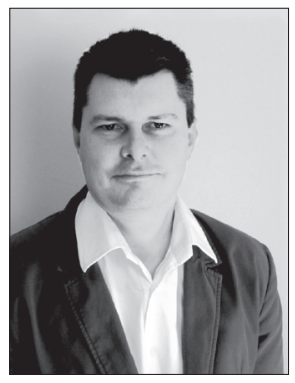

Norbert TUŚNIO, PhD, Eng.

Date of birth: 1975.

Education: MSc (Eng) degree in Fire Safety Engineering, The Main School of Fire Service (Warsaw), Faculty of Fire Safety Engineering; PhD studies in Institute of Fundamental Technological Research, Polish Academy of Sciences, Department of Computational Science, Specialization: civil engineering.

Affiliations and functions: assistant professor, The Main School of Fire Service, Faculty of Fire Safety Engineering.

Research interest: the use of drones in the State Fire Service operations and monitoring. Publications: author of 4 scientific articles (ISI Master Journal List).

\begin{abstract}
Satellite monitoring systems can be used for remote monitoring of the atmosphere over a given area but they do not provide information on the state of pollution at a given time. Additional information could only be obtained after several days. Measurements from an aircraft may be obtained almost at real-time and in different geometries - vertical and horizontal. The future of this type of monitoring is remote-controlled unmanned aerial vehicles (airplanes, helicopters and balloons tethered), equipped with telemetric monitoring.
\end{abstract}

Keywords: pollution, monitoring, unmanned aerial vehicle.

\section{Introduction}

Atmospheric pollution consists of dust, gases and liquid vapours emitted by natural sources (e.g. fermentation processes, forest fires) or by anthropogenic sources (industrial plants, transport). Gas pollution coming from natural sources is mostly: carbon oxide, carbon dioxide, sulphur dioxide, hydrogen sulphide and ammonia, while pollution of anthropogenic origin includes: nitrogen oxide, hydrocarbon, mercury vapour, carbon monoxides, sulphur monoxides and volatile organic compounds.

The assessment of atmospheric pollution is carried out in accordance with Environmental Law and EU Directives, which stipulate the methods and the scope of evaluation of substance levels in the air. They also determine: threshold values (the upper and lower thresholds of the acceptable substance levels) and the acceptable frequencies for overrunning the thresholds.

Apart from the concentration of substances contaminating the atmosphere, their transport and dispersion are also relevant. The decisive elements here are wind speed, thermal structure (including the thermal inversion) of the atmospheric boundary layer (i.e. its lower part located next to the ground). The thermal inversion and the occurrence of inhibition layers resulting there significantly change pollution transportation.

The main aims of atmosphere monitoring are:

- the verification of air quality and its compliance with normative requirements;

- detection of emission sources and determination of their contribution.

Air is the main and quickest way of transmitting pollution among other parts of the environment. In case of harmful chemical or biological agent breaks into the atmosphere, a monitoring device with a range of even several-hundred meters provides a time reserve of several minutes in order to raise the alarm and to take protective actions. This is why remote monitoring devices are used for air monitoring (Borysiewicz et al. 2013; Drzeniecka-Osiadacz, Netzel 2010; Fizykochemiczne ... 1998; Prawo ... 2008).

\section{Analysis of technical capability of remotely monitoring air pollution}

A satellite monitoring system could be used for remote monitoring of a given area. Satellite measurements would provide information about the actual pollution levels. Additional information would be received after several days. Moreover, electromagnetic radiation from the optical band (utilized commonly in remote monitoring systems) is sensitive to cloudiness; therefore, pollution monitoring of the lower parts of the atmosphere via satellite is ineffective (Borysiewicz et al. 2013; Prawo ... 2008; Prel et al. 2010).

In this regard, atmospheric pollution studies are carried out by stationery, ground-based devices or from boards of ground vehicles and aircraft.

Aerial measurements can be carried out both in horizontal and vertical geometry. Future devices for this type of monitoring are remote-controlled unmanned aircraft (aeroplanes, choppers and balloons suspended by cables (Figs 1-6), fitted with appropriate monitoring devices.

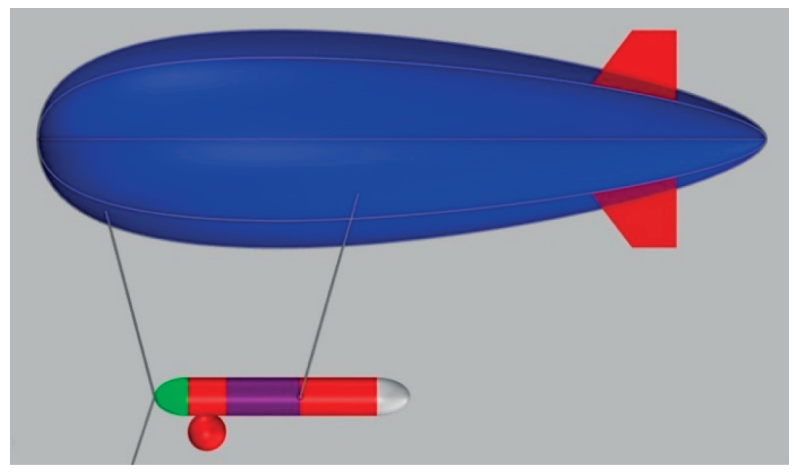

Fig. 1. K28 aerostat, side view 


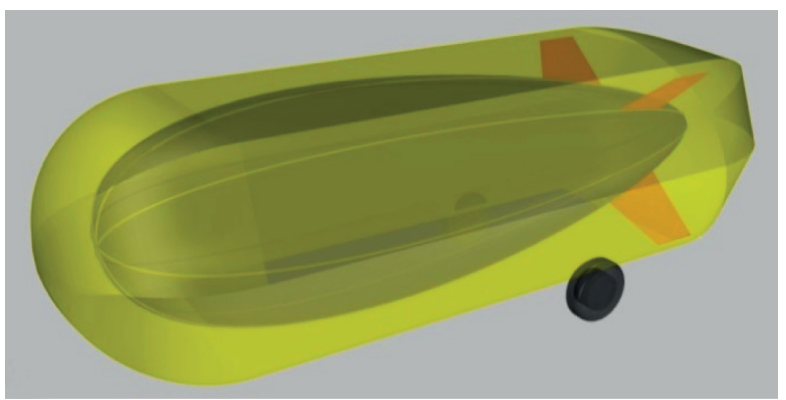

Fig. 2. K28 aerostat, inside the transport system

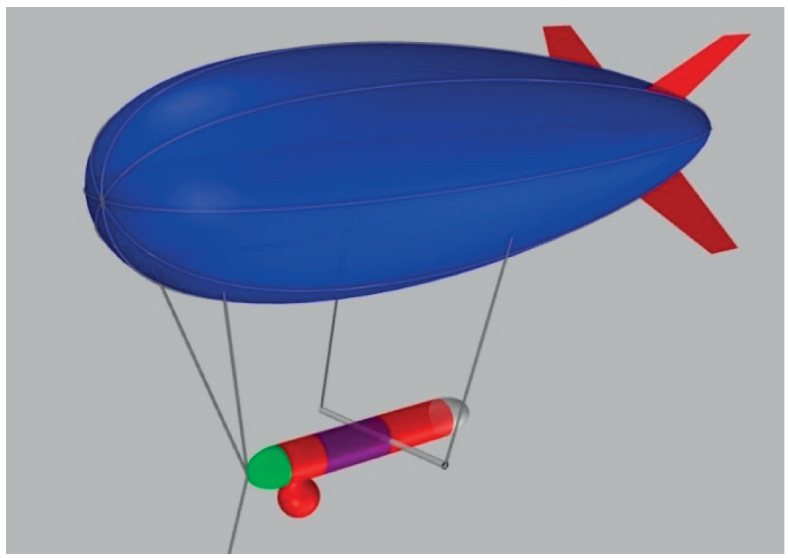

Fig. 3. K28 aerostat

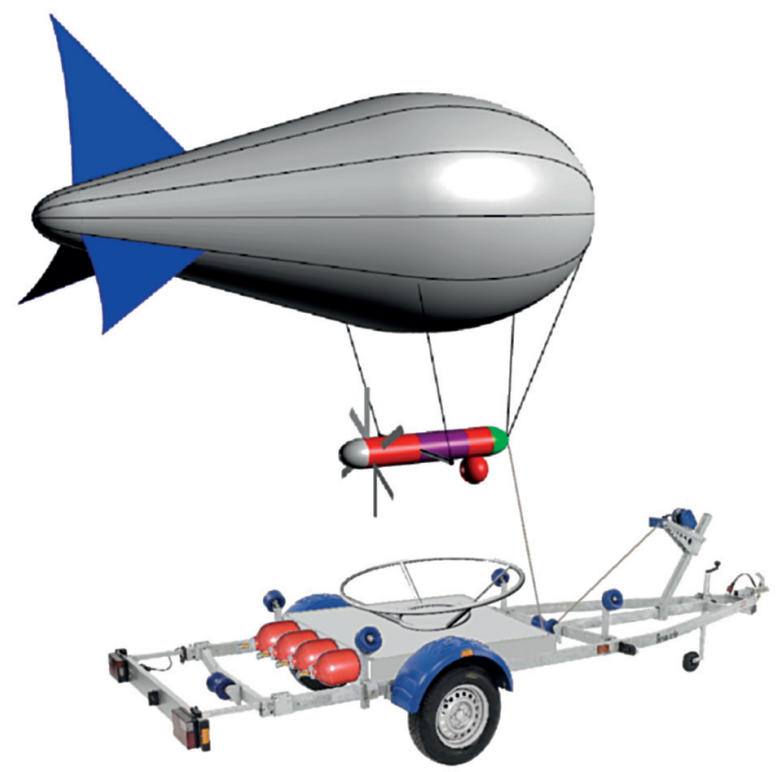

Fig. 4. K4 balloon system utilized for back translation of data transmission, telecommunication and remote observation of the mini-BSP unmanned aircraft

The operation of devices used for remote (teledetective) detection of atmospheric pollution, determining its composition and level is based on spectral analysis of electromagnetic radiation in the optical band (from the ultraviolet through visible spectrum to infrared).

The absorption and emission spectra of atmospheric gases come from oscillatory-rotary radial transitions and are characteristic for a given particle or a radical; therefore, they can be used for the identification of a given pollution constituent. On the basis of spectral analysis of the atmosphere, the presence of a chosen constituent can be verified, as well as its concentration and its possible specific distribution.

Teledetective devices can be either active or passive. Devices which enable the analysis of absorption spectra of detected gas pollutions belong to the former group and are referred to as lidars.

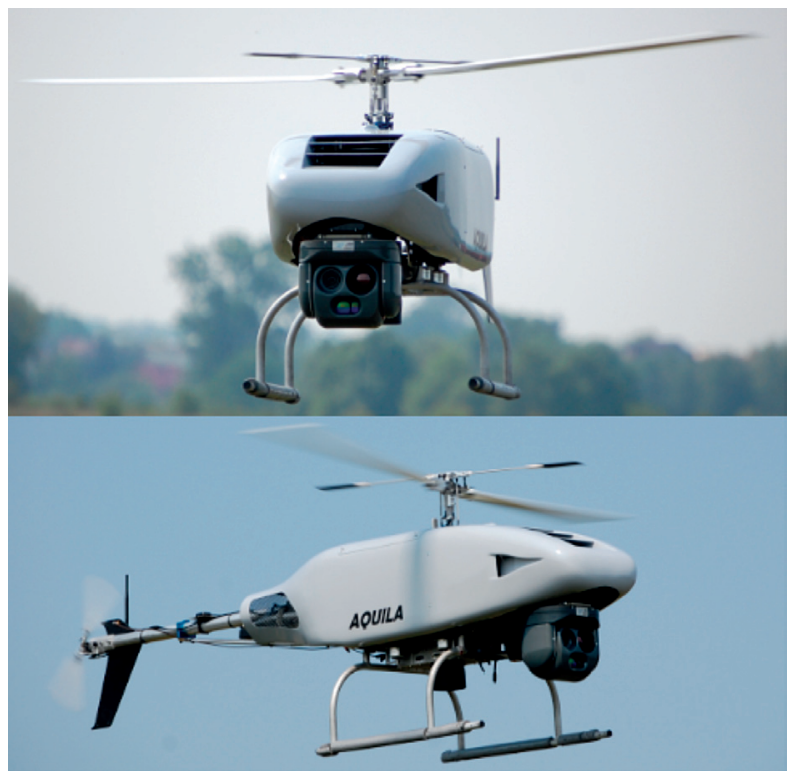

Fig. 5. The unmanned aircraft developed in the Faculty of Mechanical Engineering and Robotics; AGH University of Science and Technology, Krakow

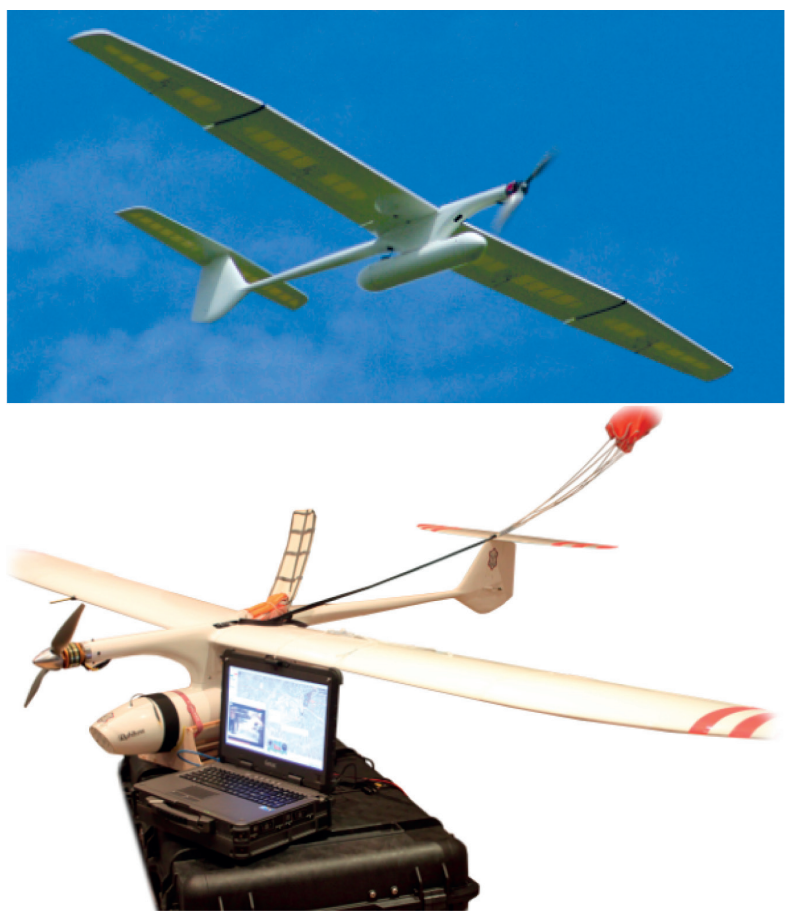

Fig. 6. The unmanned aircraft developed in the Military University of Technology 
Daylight or thermographic cameras belong to the passive group. A lidar (LIDAR - Light Detecting and Ranging) is an optoelectronic device used for remote monitoring of the atmosphere by means of dispersed light beam (e.g. laser beam), which is characterized by transverse size, divergence and spectral composition (Ernst 1997; Mierczyk 2007, 2011; Włodarski et al. 2011).

Parameters of the dispersed beam (or beams) are compared with the respective parameters of the probing beam and the information about the atmosphere's condition is obtained.

The following types of lidars are distinguished: dispersive (mono and multifrequency) used for the study of aerosol, DIAL (Differential Absorption Lidar) intended for gas contamination search, e.g. ozone, $\mathrm{NO}_{2}$, fluorescent lidars, which are called FLIDAR (Fluorescence Lidar), operating at a very wide application spectrum and coherent lidars, also referred to as Doppler lidars, which are used for wind speed measurement. It is common that device names indicate their specific properties. Raman lidar, as the name indicates, functions on the base of Raman spectrum detection of the atmosphere.

A dispersive lidar is composed of a laser, a receiver (telescope + radiation detector) and a computer controlling the measurement and data archiving. The impulse laser enables generation of strong impulses of very short duration, which allows obtaining better sensitivity and a spatial resolving power of the obtained results. An impulse laser sends short and strong impulses at such a wavelength, which is not absorbed by natural gas components of the atmosphere. An optical system channels the laser radiation beam in the desired direction. Light encounters various obstacles, dust or aerosol, undergoes dispersion in all directions, also backwards, so some of the light returns towards its source. The returning dispersed radiation (called echo) is collected by a telescope and is channelled to a detector measuring its intensity. The light intensity detector is a photomultiplier or a photodiode. The electronic circuit of a lidar synchronizes the measurements. A computer controls all. The location of the laser beam dispersion source is read according to the measurement of time, which passed from the moment of sending the impulse to the return of the dispersed light. Returning beam intensity depends on concentration of the factor, which caused the dispersion.

Dispersive lidars usually provide a good spatial resolving power (about $6 \mathrm{~m}$ by $200 \mathrm{~ns}$ of laser impulse duration) and enable detection of aerosol or gas particles, their location and concentration evaluation; however, they do not identify them in terms of chemical composition.

Differential absorption lidars (DIAL) utilize the radiation absorption phenomenon at a specific wavelength according to polluting substances.
This device consists of:

- transmitter (laser, periscope);

- receiver (telescope, filter, photodetector);

- data acquisition circuit (computer).

Apart from a tuneable laser the transmitter also contains a manifold system of optical frequency multiplier (nonlinear crystals). Due to that, not only infrared but also ultraviolet and blue adjustable radiation sources can be disposed of. A special modulator enables laser action reduction at unaffected energy, which significantly raises the laser's impulse power (operation with the so called giant impulse). Two different laser beams are utilized. One is equal to the wavelength absorbed by a marked gas; the second slightly differs from the first beam but is not absorbed or is absorbed very weakly by the marked gas, and serves as a reference beam. If there is no absorbing substance along the way of the beam, the diffused radiation intensity will change over time in the same way. However, if, for example, an absorbing substance appears in a cloud of radiation dispersing smoke, the absorbed beam intensity will be smaller. A typical range of the DIAL lidar is $10 \mathrm{~km}$.

Differential Absorption Lidars enable detection and concentration evaluation of a given substance. Furthermore, they have a very good resolving power of the detected pollution concentration (expressed in $\mathrm{mg} / \mathrm{m}^{3}$ ) they can reach the level of ppm or ppb (part per bilion).

To estimate the content of $\mathrm{NO}_{2}$ and $\mathrm{O}_{3}$ in upper parts of the atmosphere lidars in which the fluorescence phenomenon is applied are employed. The laser of a fluorescent lidar emits electromagnetic radiation in the form of impulses at a wavelength absorbed by the marked substance, which activates its fluorescence.

The emitted substance radiation is focused by a telescope and channelled to the detector. The fluorescence spectrum or the wavelengths at which the maximal luminosity occurs are characteristic for given substances and are the basis for their identification.

Fluorescent lidars are not suitable for measurements in the troposphere and the lower parts of the stratosphere. High pressure which is present there makes the crash deactivation processes of the activated molecules or atoms much more probable than radial processes. Thus, fluorescence is almost suppressed and the method proves ineffective.

For selective gas detection raman lidars are also utilized. The radiation diffusion on gas particles is connected with the wavelength shift (Raman scattering), which is typical for every substance. The laser sends signals at a particular wavelength and the detector receives only electromagnetic radiation at the length of the shifted wave against laser impulse wavelength. Raman lidars are not very sensitive (their resolving power is about $100 \mathrm{ppm}$ ) and are used for detection of highly concen- 
trated gases present in the atmosphere, such as $\mathrm{H}_{2} \mathrm{O}$, $\mathrm{CO}_{2}, \mathrm{O}_{2}$ and $\mathrm{N}_{2}$. The range of Raman lidars is several hundred meters.

Daylight cameras as stand-alone devices have a rather narrow application in atmospheric pollution monitoring - they comprise only a part of a structure, in which they are coupled with thermographic cameras. The newest generations of thermographic cameras are increasingly more used for air condition monitoring (Chwaleba et al. 2013; Korski 2010; Pomiary ... 2004; Więcek 2010). Thermographic cameras are devices which enable remote temperature measurements of objects emitting electromagnetic radiation in "thermal" range bodies with a higher temperature than absolute zero. Have the capability of emitting such radiation, which is referred to as infrared radiation. Infrared radiation energy values rise together with the increase of object temperature. Therefore, object temperature measurement is possible by means of measurement of emitted energy value in the infrared radiation band - named shortly infrared. The wavelength of this radiation is divided into four subranges:

$-0,75-3 \mu \mathrm{m}-$ near infrared;

- 3-6 $\mu \mathrm{m}$ - mid infrared;

- 6-15 $\mu \mathrm{m}$ - far infrared;

- 15-1000 $\mu \mathrm{m}$ - extreme infrared.

Modern thermographic cameras comprise an optical system (containing a lens and narrowband filters), a matrix converter (detector) and circuits: signal conversion, archiving and imaging circuit).

The main task of the thermographic camera lens and its accompanying optical elements is to focus infrared radiation emitted by the observed object on the measuring converter (detector). Its next function is to improve the utile signal relation with noise (babble signal), which is implemented by matching an appropriate spectral permeability. This procedure allows ensuring a very good lens transparency in the range of working wavelengths (usable signal) and a weak radiation permeability coming out of this range (noise).

A converter (detector) of infrared radiation is one of the most important blocks in the thermographic camera structure, because it converts infrared radiation into an electric signal (usually into a current signal, which is afterwards converted into a voltage signal in an analogue circuit). This conversion should be effective in infrared radiation bands, in which it is easily permeated by the atmosphere. Because of strong infrared radiation suppression in the atmosphere in the band of 5-7 $\mu \mathrm{m}$, thermographic cameras (thus infrared detectors) operate at a short wavelength in the band of 3-5 $\mu \mathrm{m}$ and at a long wavelength in the band of 8-14 $\mu \mathrm{m}$.

The detectors constructed can be cooled or noncooled. Modern infrared detectors are constructed as matrixes - containing up to a few millions of sensors (test points - pixels). Due to this, they are characterized by the so called dimensional resolution, which is equal to the production of the amount of sensors (pixels) in the $\mathrm{N}$ horizontal and $\mathrm{M}$ vertical direction. For instance, it can amount to $\mathrm{N} \times \mathrm{M}=640 \times 480$. It is a significant parameter of thermographic cameras. At a constant distance between a camera and an object, as well as with the increase of dimensional resolution of the detector the thermogram quality improves - the sensor (pixel) covers a smaller object surface. Hence, a more precise result is obtained, which is the average temperature of the surface "seen" by the sensor.

Infrared detectors according to the physical basis of their function are classified into two groups:

- thermal (thermoelectric) - bolometers, pyroelectric;

- photon (photoelectric) - photoconductive (photoresistors), photovoltaic (photodiodes), on QWJP quantum wells (Quantum Well Infrared Photodetector).

A considerable majority of sold cameras are cameras operating in far infrared with measuring converters registering radiation at a wavelength in the range of about 8-14 $\mu \mathrm{m}$.

From the viewpoint of thermographic measurements, the most significant parameters for the user are those which allow performing required measurements, such as:

- thermal resolving power (10-200 $\mathrm{mK}$ );

- spatial resolution - conditioned by a matrix detector resolving power and dimensions of individual sensors;

- camera operation frequency - corresponding to the frequency of electric signal reading from individual matrix sensors $(25-100 \mathrm{~Hz})$.

In currently manufactured thermographic cameras non-cooling bolometric matrix detectors having $320 \times 240$ pixels, a temperature resolving power of $20-200 \mathrm{mK}$ and a photoemissive with quantum matrix detectors (QWIP) are applied most frequently. QWIP detectors require cooling to the temperature of $\sim 70 \mathrm{~K}$ with the aid of Stirling cooler together with Dewar flask. Their temperature resolving power lies in the level of $10-40 \mathrm{mK}$. They obtain the best resolving power in the long-wave band, and the matrix dimensions are equal to $640 \times 480$ pixels.

Thermographic cameras can be used indirectly for atmospheric pollution monitoring - by identifying the emission source. Cameras with short and long-wave detectors and appropriate filters are employed. Cameras allowing short-wave detection enable detection of such gases like: benzene, butane, ethane, ethylbenzene, ethylene, heptanes, hexane, isoprene, methyl ethyl ketone, methane, methanol, octane, pentane, propane, 
propylene, toluene, xylene, etc. It can be stated that short-wave detection is mostly applicable in the petroleum industry. Long-wave detection may be applicable in petroleum industry, power engineering, and chemical industry. It qualifies for the detection of the following gases: $\mathrm{SF}_{6}$, ethyl cyanoacrylate, $\mathrm{NH}_{3}, \mathrm{ClO}_{2}$, acetic acid, freon, ethylene and methyl ethyl ketone (Chwaleba et al. 2013; Monitoring ... 2013; Włodarski et al. 2011).

Present thermographic cameras are also applied for direct monitoring by dint of utilizing quantum thermographic cameras with narrowband filters. These filters have to be adjusted to the absorption bands of gas-pollutions. Thermographic cameras obtain images of the changes of radiation transmission along the pollution pathway. In these cameras, software realizing the fast Fourier transforms and the cooled QWIP detectors are utilized, which work as spectroradiometers.

A cheap alternative for the pricy technology of the cooled cameras could be the non-cooled microbolometer camera technology. The disadvantage of this technology is that it detects only a considerably smaller amount of gases, firstly, greenhouse gases.

For the monitoring of transport and dispersion of atmospheric pollution active and passive devices and methods are utilized, enabling the measurement of wind speed and atmosphere's thermal structure, actually its boundary layer. If there is wind a three-dimensional field of its speed is defined. For a remote wind measurement two types of active devices are utilized radars and lidars.

Radar devices enable obtaining wind profile. Radar devices send short energy impulses at a radio frequency, which are dispersed by the heterogeneity of the atmosphere, and this gives the spectrum of Doppler shift. Many types of wind profiling radar devices, which are able to cover the heights from the ground level to the lower troposphere, are available. The Doppler beam sweep is used most frequently. It involves the change of the radar beam direction and measurement of Doppler shift in the range function (height) in several directions. The environmental vector velocity is determined on the basis of radial constituent for each direction. Another method, referred to as profile fixing by means of distant antennas, involves sending a single vertical radar beam and measuring the shifts in the signal phase between the numerous adjacent antennas in order to obtain the vector wind profile.

Doppler meteorological radars operating at wavelengths of 3, 5 and $10 \mathrm{~cm}$ can be used for the measurement of the hydrometer radial component velocity, while the circuits operating at longer wavelengths may measure the velocity in clean air in the range of a few kilometres. Meteorological radars are especially useful for a quantitative estimation of wet rainfalls because of the ability of detecting rainfalls and estimating rain scale over large areas with a reasonable precision. Wind profiling radars may detect and identify rainfall; however, they only collect a single profile, while meteorological radars provide volumetric distribution for large areas. Multiparameter radars send and measure reflected signals both for horizontally polarized beams, as well as vertically, which allows distinguishing the type of precipitation (e.g. rain, snow, hail) and estimate quantity in a more accurate way. Their application for monitoring of the lower part of the atmosphere is limited, because they do not provide the best vertical resolving power (60$75 \mathrm{~m}$ ) at the minimal height of $150 \mathrm{~m}$. For wind speed measurement a Doppler lidar, which uses the Doppler measurement of the laser radiation shift diffused by aerosol molecules moving at wind speed, is utilized. It can be used for the measurement of wind speed or dynamics of different kinds of atmospheric turbulence. Slight frequency shifts cause serious measurement problems. Even for a very strong wind blowing at the speed of $100 \mathrm{~km} / \mathrm{h}$ the spectral line shift in near ultraviolet is only about $100 \mathrm{MHz}$. This is why Doppler lidars require lasers with a very narrow and stable line, which enable heterodyne detection based on signal mixing and measurement of differential frequency. Diffusing lidars ensure wind speed measurement with the accuracy of $0,5 \mathrm{~m} / \mathrm{s}$ with a vertical resolving power of $15 \mathrm{~m}$. Lidar devices used for measurement of wind speed are from the meteorological point of view unbeatable, in comparison to radars, but they are more expensive.

One of the estimation methods of the atmosphere's thermal structure, occurrence detection and the range of thermal inversion is an acoustic survey. SODAR (Sound Detection and Ranging) is an acoustic equivalent of commonly used radars.

An acoustic survey carried out with the use of sodar is an example of active teledetection. The basis for which is an acoustic impulse emitted into the atmosphere, and then registering of the part of the signal returning towards the ground (atmospheric acoustic echo). This echo develops as a result of multiple dispersion of the emitted acoustic wave beam into the atmosphere through the thermal air heterogeneity.

The characteristic forms of atmosphere acoustic echo showed on a sodar picture may be associated with the structure of atmosphere's boundary layer. The vertical echoes coincide with convention cells, the layer echoes signalize the presence of thermal inversion and the anechoic cases represent the adiabatic gradient. The acoustic survey allows the assessment of the thermal-turbulent structure of the atmosphere's boundary layer. Its main advantage is a precise time resolving power - a few seconds with a relatively high horizontal reach (up to $1 \mathrm{~km})$. 
Also, previously mentioned types of lidars allow the estimation of thermal structure of the atmosphere, especially its boundary layer. Among passive devices used currently for estimation of atmosphere's thermal structure, single-frequency scanning microwave radiometers and thermographic cameras are common.

Radiometers enable gaining atmospheric thermal structures up to the height of 600-1000 m, with a $50 \mathrm{~m}$ vertical resolving power.

However, thermographic cameras mounted on soaring remote controlled unmanned aeroplanes or choppers are able to determine the thermal structure of the atmosphere boundary layer precisely.

\section{Conclusions}

The carried out analysis proved that:

1. The most appropriate monitoring devices to be placed on boards of outsize aircraft are lidars, due to their functionality (in terms of collecting pollution identification and assessing their distribution) and precision. They can be placed on patrolling, manned aeroplanes and choppers and outsize unmanned planes because of their (still) significant dimensions and weight, not to mention the structure complexity and price.

2. It seems that on small-unmanned aeroplanes and choppers thermo graphic cameras with a very good resolving power and spatial resolution should be mounted.

3. While developing the atmospheric pollution monitoring system for a given aircraft, uniform equipment should be utilized (in terms of its principle of operation, technology, manufacturing, etc.). This would facilitate the design, construction and utilization of the monitoring system.

\section{References}

Borysiewicz, M.; Garanty, I.; Kozubal, A. 2013. Wymagania w Zakresie Modeli Dynamiki Atmosfery i Transportu Skażeń na Potrzeby Systemów Zarządzania Sytuacjami Kryzysowy$m i$ [Requirements for models of atmospheric dynamics and transport of contaminants to the needs of crisis management systems] [online], [cited 10 October 2013]. Available from Internet: http://manhaz.cyf.gov.pl (in Polish).

Chwaleba, A.; Poniński, M.; Siedlecki, A. 2013. Metrologia Elektryczna. Warszawa: WNT (in Polish).

Drzeniecka-Osiadacz, A.; Netzel, P. 2010. Ocena rozkładu wysokości inwersji nad Wrocławiem na podstawie sondażu akustycznego [Rating distribution of the amount of inversion over Wrocław based on acoustic survey], in Proceedings of ECOpole, 14-16 October, 2010, Opole, Poland (in Polish).

Ernst, K. 1997. Lidary w badaniach atmosfery, Wiedza i Życie (6) (in Polish).

Korski, J. 2010. Termowizja w monitoringu i zwalczaniu pożarów składowisk odpadów pogórniczych, Górnictwo i Geologia 5(2) (in Polish).
Mierczyk, Z. 2007. Laser systems for stand-off detection of contamination and pollution of atmosphere, in Proc. of SPIE "Laser Technology VIII: Applications of Lasers" 6598: 112-120.

Mierczyk, Z. 2011. Analiza aktualnych zagrożeń bezpieczeństwa, Ochrona przed skutkami nadzwyczajnych zagrożeń. Vol. 2. Warszawa: WAT. 10 p. (in Polish).

Monitoring Zanieczyszczeń i Rozprzestrzenianie Skażeń w Atmosferze 2013 [online], [cited 10 October 2013]. Available from Internet: www.kosmos.gov.pl

Fizykochemiczne Metody Kontroli Zanieczyszczeń Środowiska. 1998. Namieśnik, J.; Jamrógiewicz, Z. (Eds.). Warszawa: WNT (in Polish).

Pomiary Termowizyjne w Praktyce. 2004. Madura, H. (Ed.). Warszawa: Agenda Wydawnicza PAKu (in Polish).

Prawo Ochrony Srodowiska. 2008. (25): 150.

Prel, F.; Moreau, L.; Lavoie, H.; Bouffard, et al. 2010. Overview of the improved compact atmospheric sounding interferometer (iCATSI) multi-pixels standoff chemical detection sensor and the MR-i imaging spectroradiometer, in Proc. of SPIE "Electro-Optical and Infrared Systems: Technology and Applications VII". Vol. 7834. Huckridge, D. A.; Ebert, R. R. (Eds.), 901-912.

Więcek, B. 2010. Wybrane Zagadnienia w Spółczesnej Termowizji w Podczerwieni. Łódź: Wyd. Politechnika Łódzka (in Polish).

Włodarski, M., et al. 2011. Zastosowanie systemu BST typu DIAL z przestrajanymi laserami $\mathrm{CO}_{2}$ do wykrywania zanieczyszczeń chemicznych atmosfery, in Ochrona Przed Skutkami Nadzwyczajnych Zagrożeń 2. Warszawa: WAT (in Polish). 